University of South Carolina

Scholar Commons

8-8-2012

\title{
Breast Tumour Initiating Cell Fate Is Regulated by Microenvironmental Cues from an Extracellular Matrix
}

\author{
Sharmistha Saha \\ University of South Carolina - Columbia \\ Pang-Kuo Lo \\ University of South Carolina - Columbia \\ Xinrui Duan \\ University of South Carolina - Columbia \\ Hexin Chen \\ University of South Carolina - Columbia, chen53@mailbox.sc.edu \\ Qian Wang \\ University of South Carolina - Columbia, wang@mail.chem.sc.edu
}

Follow this and additional works at: https://scholarcommons.sc.edu/chem_facpub

Part of the Biochemistry Commons, Cancer Biology Commons, Medicinal-Pharmaceutical Chemistry Commons, Molecular Biology Commons, and the Organic Chemistry Commons

Publication Info

Published in Integrative Biology, Volume 4, Issue 8, 2012, pages 897-904.

(c) Integrative Biology 2012, Royal Society of Chemistry.

This Article is brought to you by the Chemistry and Biochemistry, Department of at Scholar Commons. It has been accepted for inclusion in Faculty Publications by an authorized administrator of Scholar Commons. For more information, please contact digres@mailbox.sc.edu. 


\title{
Breast tumour initiating cell fate is regulated by microenvironmental cues from an extracellular matrix $\dagger$
}

\author{
Sharmistha Saha, ${ }^{a}$ Pang-Kuo Lo, ${ }^{b}$ Xinrui Duan, ${ }^{a}$ Hexin Chen $* b$ and Qian Wang* ${ }^{a}$ \\ Received 20th February 2012, Accepted 2nd May 2012 \\ DOI: $10.1039 / \mathbf{c} 2 \mathrm{ib20034a}$
}

Cancer stem cells, also known as tumour-initiating cells (TICs), are identified as highly tumorigenic population within tumours and hypothesized to be main regulators in tumour growth, metastasis and relapse. Evidence also suggests that a tumour microenvironment plays a critical role in the development and progression of cancer, by constantly modulating cell-matrix interactions. Scientists have tried to characterize and identify the TIC population but the actual combination of extracellular components in deciphering the fate of TICs has not been explored. The basic unanswered question is the phenotypic stability of this TIC population in a tissue extracellular matrix setting. The in vivo complexity makes it difficult to identify parameters in a diverse milieu that affect TICs behaviour. Herein we studied how the TIC population would respond when subjected to a unique microenvironment composed of different extracellular proteins. The TIC-enriched population isolated from a Her2/neu-induced mouse mammary tumour was cultured on collagen, fibronectin and laminin coated substrates for one to two weeks. Our observations indicate that a laminin substrate can maintain the majority of the self-renewing and tumorigenic TIC population, whereas collagen induced a more differentiated phenotype of the cells. Also interestingly, fibronectin substrates dictated an invasive phenotype of TICs as evidenced from the EMT-related gene expression pattern. The results of this study signify that the microenvironmental cues play a considerable role in tumour relapse and progression by altering the cancer stem cell behaviour and thus this knowledge could be used to design novel cancer therapeutics.

\section{Introduction}

Cancer Stem Cells (CSCs), also known as tumour-initiating cells (TICs), are a highly tumorigenic population that exist as a

${ }^{a}$ Department of Chemistry and Biochemistry \& Nanocenter, University of South Carolina, Columbia, SC 29208, USA.

E-mail:wang@mail.chem.sc.edu

${ }^{b}$ Department of Biological Science, University of South Carolina,

Columbia, SC 29208,USA. E-mail: chen53@mailbox.sc.edu

$\dagger$ Electronic supplementary information (ESI) available: Supplementary figures, primer table and water contact-angle information. See DOI: $10.1039 / \mathrm{c} 2 \mathrm{ib} 20034 \mathrm{a}$ subset within tumours and have been hypothesized to be main regulators in tumour growth, metastasis, and relapse. ${ }^{1-3}$ Characterizing their phenotype and analyzing the underlying mechanism that confers to their tumour initiating properties have significance in the field of cancer biology. ${ }^{4}$ The isolation of CSCs has been reported from various human solid tumours like breast, colon and brain tumours. ${ }^{5}$ Although the origin of CSCs is not clearly understood, it has been shown to share several cell surface markers and molecular signatures with normal embryonic and adult stem cells, together with selfrenewing potency and differentiation ability. ${ }^{6}$

\section{Insight, innovation, integration}

Cancer Stem Cells (CSCs) are identified as highly tumorigenic population within tumours and considered regulators in tumour growth, metastasis and relapse. Evidence also suggests that a tumour microenvironment plays a critical role in the cancer progression, by constantly modulating cellmatrix interactions. The basic unanswered question is the phenotypic stability of this CSCs population in tissue extracellular matrix setting. The in vivo complexity makes it difficult to identify parameters in a diverse milieu that affect CSCs behaviour. In this paper we have utilized 2D ECM coatings to evaluate CSCs response combined with biological analysis of the functional properties of these cells. This paper provides a better understanding of the cell-substrate interactions taking place in a tumor microenvironment and thus this knowledge has implications in designing novel biomaterials for developing cancer therapeutics. 
Adult stem cells sustain a balance between self-renewal and differentiation, which is critical for maintaining tissue homeostasis. In 1978 Schofield proposed the existence of a "niche" or a specialized compartment in hematopoietic stem cells that might provide a physiological microenvironment to create a balance between these two key processes. The niche composed of supportive cells and ECM probably regulates stem cell fate by an interacting mechanism which involves creating cytokines gradient, matrix stiffness and the presence of immobilized signalling molecules. ${ }^{7}$ After knowing the vital role played by the normal stem cell niche in maintaining stem cell fate, it is logical to assume the existence of a "CSC niche" or tumour niche which can similarly regulate CSCs behaviours.

In breast cancer one of the most important questions yet to be answered is whether breast CSCs originate from normal mammary stem cells. ${ }^{8}$ It can be assumed that both breast CSCs and normal mammary stem cells may reside in a special compartment adjacent to fully differentiated cells but maintain their progenitor status. Little is known, however, about the specific ECM cues that interact with the cells to either retain quiescence or drive the cells to a definite course. ${ }^{9}$ The major structural protein in the mammary gland is fibrillar collagen, which is in close contact with a highly organized and specialized ECM region named the basal lamina that in turn separates the epithelium from the underlying stroma. ${ }^{10}$ The proteins comprising the basal lamina were classically identified as collagen IV, laminins, entactins and proteoglycans. Tumour stroma undergoes remodelling during carcinogenesis and also sometimes prior to tumour formation by allowing deposition of collagen I in a random orientation with other ECM proteins like fibronectin. ${ }^{11}$ These ECM proteins bind to specific cell surface receptors known as integrin proteins and can induce integrin signalling. Several integrin proteins have been shown to be over-expressed in CSCs, which signifies that receptors of these integrins are present in the surrounding matrix and are key drivers of the CSC fate.

Scientists have tried to characterize and identify the CSCs population but the actual combination of extracellular components in deciphering the CSCs fate has not been explored. The basic unanswered question so far has been the phenotypic stability of this tumour initiating population of cells in a tissue microenvironment. It will be very important to address the functional properties and gene expression profile of these cells to predict their fate. If we can identify cues from a microenvironment that regulates CSCs activity in vitro, it would have important implications in designing suitable ex vivo model systems to study these cells and in designing proper therapeutic targets.

Recently in our lab we identified a TIC population in a Her2/neu-induced mammary tumour that was characterized by enhanced expression of CD49f and CD61 integrin markers. ${ }^{12}$ This enriched population demonstrated higher in vitro tumorsphere formation, clonogenicity and in vivo tumorigenicity, keeping with the CSC hypothesis. ${ }^{12}$ In this paper we report the study of using this TIC model to explore its responses to various extracellular matrix components like collagen-I (Coll-I), fibronectin (Fn) and laminin-I (Lam-I). The inherent characteristics of these cells to undergo differentiation and selfrenewal under the influence of different ECM proteins were evaluated. The results of this study indicate that the microenvironmental cues from the ECM play a significant role in tumour progression and development and can be a novel target for designing cancer treatment.

\section{Results}

We previously reported that Her2/neu-induced mouse mammary tumour cells can be enriched for TICs by sorting using a combined expression of integrin markers CD49f and CD61. ${ }^{12} \mathrm{H} 6 \mathrm{O} 5$ cells were subjected to FACS sorting and $\mathrm{CD} 49 \mathrm{f}^{\text {high }} \mathrm{CD} 61^{\text {high }}$ population of cells characterized previously with higher stem/progenitor phenotype and enhanced tumorigenicity ${ }^{12}$ were isolated and cultured on ECM coated substrates (Fig. 1a). Sorted cells were immediately seeded on Coll-I, Fn and Lam-I substrates keeping TCP as a control and cultured for 1 to 2 weeks. As seen from phase contrast micrographs (Fig. 1b), sorted H6O5 cells propagated on Coll-I and Fn in a well-spread adherent monolayer similar to the TCP control. In comparison, sorted $\mathrm{H} 6 \mathrm{O} 5$ cells exhibited a more clustered morphology on Lam-I, with adherent islands of cells clumped together. Cells were passaged and maintained on the coated substrates every 2-3 days up to 2 weeks. Similar cell morphology on each ECM coated matrix was observed with each subculturing and propagation till 2 weeks. Trypsinization of cells during passaging on Coll-I, Fn and TCP required 10 minutes at $37{ }^{\circ} \mathrm{C}$ whereas only required 5 minutes for Lam-I matrices. As a control study we also tested the morphology of $\mathrm{H} 6 \mathrm{O} 5$ cells on poly-D-lysine coated TCP and uncoated TCP. No difference in morphology was observed and cells grew and propagated normally (Fig. S1, ESI $\dagger$ ).

The impact of ECM proteins on the maintenance of the TICs population was examined by monitoring the signature integrin expression profile. FACS sorted tumour initiating H6O5 cells were cultured on Coll-I, Fn, Lam-I and TCP control, respectively, for 1 to 2 weeks; and at the end of each week flow cytometry studies were conducted to evaluate the expression levels of CD49f and CD61 markers. As shown in Fig. 2, the percentage of the CD $49 \mathrm{f}^{\text {high }} \mathrm{CD} 61^{\text {high }}$ population after week 1 was significantly higher in sorted H6O5 cells cultured on Lam-I coated substrates (49.9\%) followed by Fn coated substrates $(34.4 \%)$. In contrast, the percentage of the double positive population significantly decreased in cells cultured on Coll-I (15.5\%), whereas the TCP control cells still retained $21.4 \%$ of this cell subset. Flow cytometry study conducted after two-week culture on the ECM coated substrates further substantiates that Lam-I maintained the highest of the double positive $(49.1 \%)$ cell pools in comparison to Fn $(31.9 \%)$, Coll-I (16.77\%) and the TCP control $(21.9 \%)$ (Fig. S2, ESI $\dagger$ ). Our previous findings report that the percentage of CD49f ${ }^{\text {high }}$ CD $61{ }^{\text {high }}$ subset reflects the TICs population in a Her-2/neu induced mouse mammary tumor. ${ }^{12}$ Therefore this result indicates that Lam-I can maintain the majority of the TIC population whereas Coll-I shows significant loss.

To confirm that the maintenance of CD49f ${ }^{\text {high }}$ CD $61{ }^{\text {high }}$ expressing $\mathrm{H} 6 \mathrm{O} 5$ cells in the ECM coated substrates also correlates with the functional aspects of the TIC population, in vitro tumorigenic and clonogenic assays were conducted. In vitro tumorigenicity was assessed by tumorsphere formation in suspension culture which is also a characteristic hallmark to identify the self-renewal properties of cancer stem cells. ${ }^{13}$ 
a.

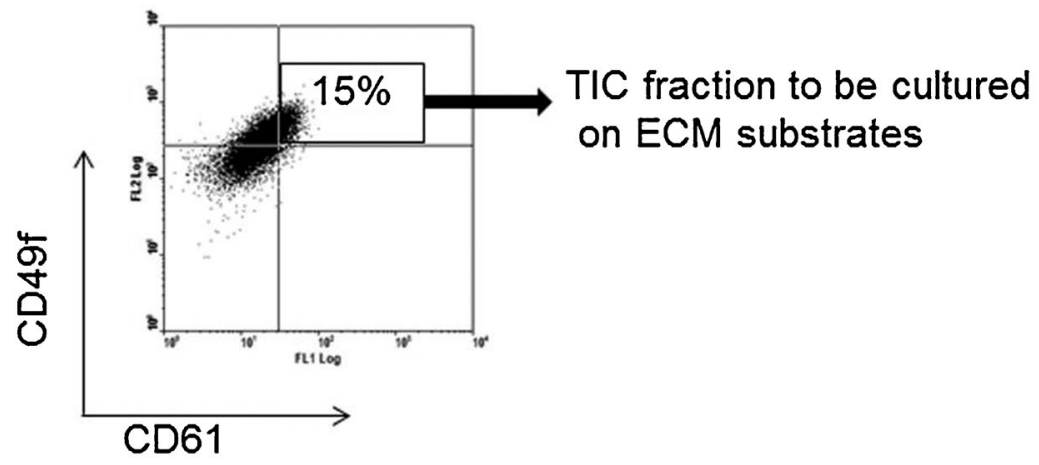

b.

Coll-I

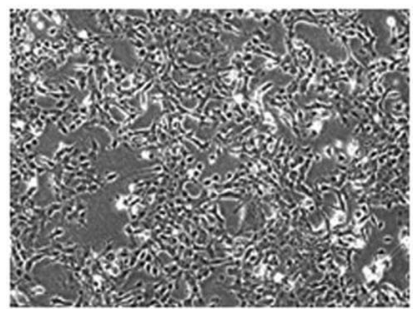

Fn

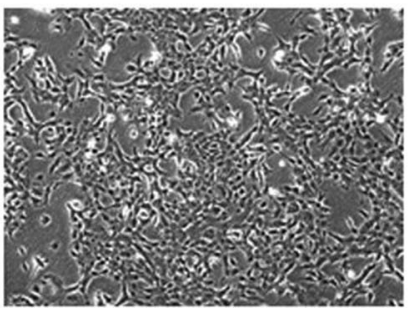

Lam-I

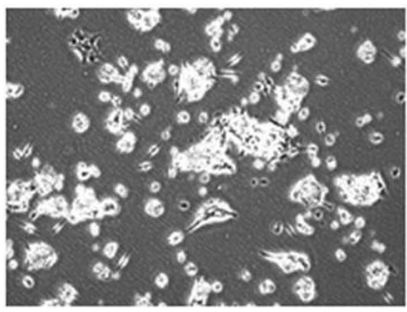

TCP

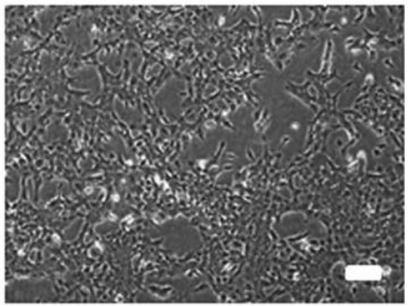

Fig. 1 (a) FACS isolation of TIC population from Her2/neu-induced primary mammary tumour H6O5 using the expression profile of CD49f ${ }^{\text {high }} \mathrm{CD} 61^{\text {high }}$, the gated cell subset $(\sim 15 \%)$ was cultured on ECM coated substrates. (b) Phase contrast micrographs of the isolated TIC-enriched population on Coll-I, Fn, Lam-I substrates and TCP control after one week of culture. Scale bar $=50 \mu \mathrm{m}$.

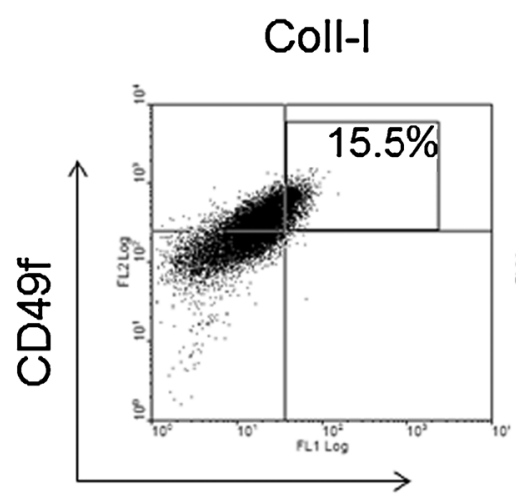

CD61
$\mathrm{Fn}$

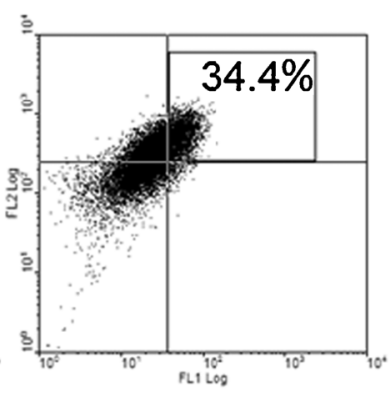

Lam-I

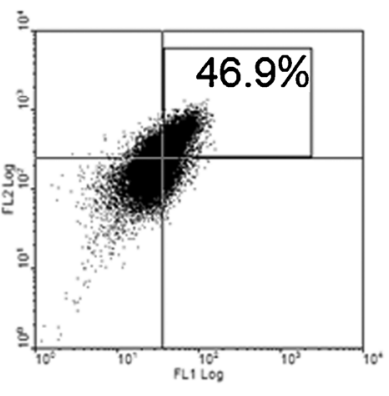

TCP

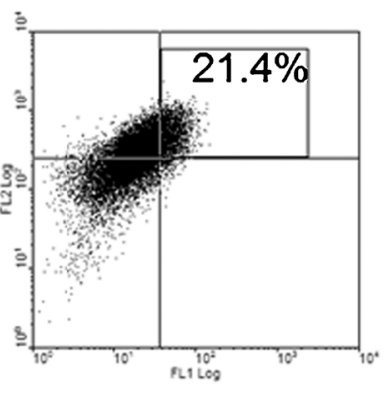

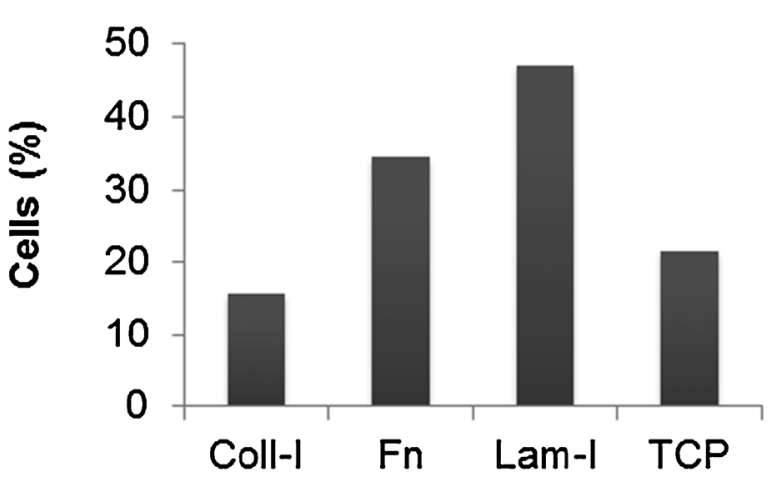

Fig. 2 FACS analysis showed that Lam-I and Fn maintained the majority of the TIC population whereas Coll-I and TCP cell cultures exhibited significant loss of TICs after one week of culture on coated substrates. The FACS analysis data were also plotted as a bar graph (the bottom panel).

In suspension culture, $\mathrm{H} 6 \mathrm{O} 5$ cells from Lam-I coated matrices showed the highest $(1.36 \pm 0.05 \%)$ tumorsphere formation efficiency after week 1 analysis. Sphere forming efficiency of
H6O5 cells on Lam-I was significantly higher $(p<0.05)$ in comparison to Fn $(0.60 \pm 0.09 \%)$, Coll-I $(0.50 \pm 0.10 \%)$ and the TCP control $(0.43 \pm 0.07 \%)$ (Fig. $3 a$ and $b)$. Efficiency was 
a.

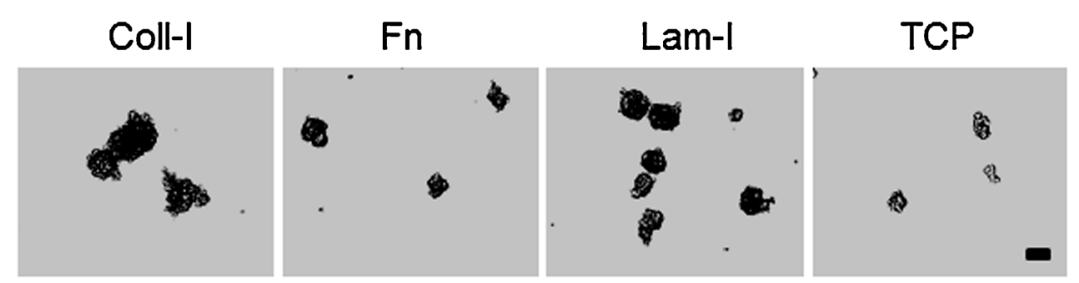

b.

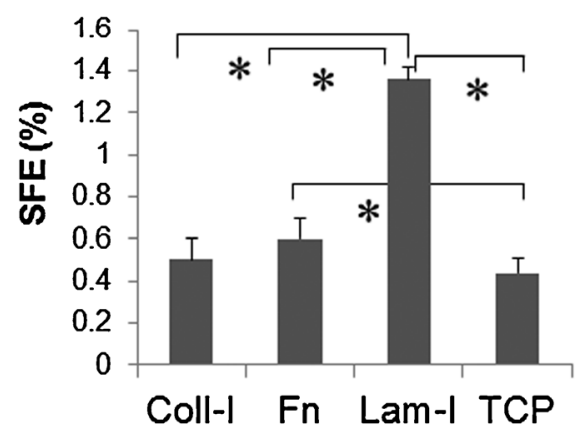

d.

C.

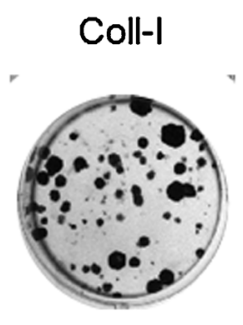

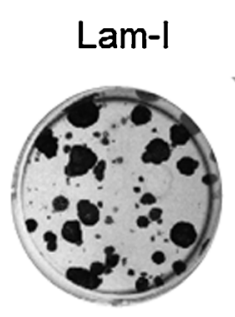
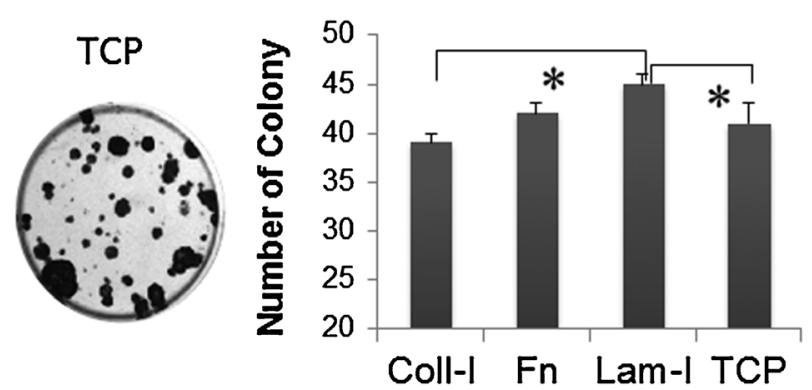

Fig. 3 TICs exhibit greatest self-renewal characteristics in Lam-I after one week of culture. (a) In vitro tumorsphere formation analysis of TICs retrieved from Coll-I, Fn, Lam-I and TCP. Scale bar $=50 \mu \mathrm{m}$. (b) Plot showing sphere formation efficiency (SFE) for each substrate. (c) In vitro clonogenic assay of TICs pre-cultured on Coll-I, Fn, Lam-I and TCP substrates. (d) Plot showing colony numbers for each substrate. All measurements were performed in triplicates and data are indicated as mean \pm standard deviation. $(*) p<0.05$ indicates a statistically significant difference.

not considerably different between Coll-I and Fn substrates but showed statistical difference between Fn and TCP control substrates, the former being higher $(p<0.05)$. Very similar results were obtained after week 2 culture on ECM coated matrices where Lam-I showed significantly higher efficiency $(1.47 \pm 0.07 \%)$ with respect to Fn $(0.71 \pm 0.03 \%)$, Coll-I $(0.57 \pm 0.01 \%)$ and the TCP control $(0.44 \pm 0.06 \%)$ (Fig. S3a and $b$, ESI $\dagger$ ).

Clonogenic potential is a common assay used to quantify the number of TICs in a heterogeneous sample. It is the ability of a single cell to generate daughter cells of its own kind and also adds to the degree of tumorigenicity and also an intrinsic property of adult stem cells. ${ }^{14}$ The TIC-enriched cell population of $\mathrm{H} 6 \mathrm{O} 5$ cells cultured on various ECM matrices was tested for clonogenic potential in a limiting dilution fashion. It was observed that $\mathrm{H} 6 \mathrm{O} 5$ cells retrieved from Lam-I coated matrices showed the highest numbers of colony in comparison to Coll-I, Fn and control TCP (Fig. 3c and d). Although significant difference is obtained between Lam-I, Coll-I and TCP control, no statistical difference was observed between Lam-I and Fn. However, 25\% of the colonies from Lam-I was greater than $2 \mathrm{~mm}$ than those from the rest of the ECM proteins. Interestingly the colony forming ability decreased from Lam-I $>$ Fn $>$ TCP $>$ Coll-I. Results from week 2 culture indicated similar phenomena (Fig. S3c and d, ESI $\dagger$ ), where cells from Lam-I showed significantly higher clonogenicity in contrast to Coll-I, Fn and TCP control. Our data signify that TICs maintained their highest self-renewing ability and tumorigenic potential in Lam-I coated substrates in contrast to Fn, Coll-I and TCP (Fig. 3b).
To evaluate the influence of different ECM proteins on the gene expression of TICs, quantitative reverse transcriptase PCR analysis was performed to examine the expression of stem cells, differentiation and epithelial-to-mesenchymal transition (EMT) related genes. The expression of differentiation markers like $K r t 18$ and $K r t 14$ was significantly up-regulated in the cells cultured on Coll-I, in comparison to Fn, Lam-I and TCP (Fig. 4a). Expression analysis of cancer stem cell markers showed that $A l d h 1,{ }^{15} C D 133^{16}$ and $A b c g 2^{17}$ expression levels were highest in cells cultured on Lam-I whereas the expression of differentiation markers in the Lam-I culture did not show significant difference to the TCP control. Interestingly, Gli1, a stem cell marker, ${ }^{18}$ was also expressed equally in Lam-I and Fn cultures, and the expression of Aldh1 in Fn cultures was significantly higher than both Coll-I and TCP cultures (Fig. 4b). The observations of up-regulation of differentiation marker genes and down-regulation of stem cell marker genes in the Coll-I culture indicate a differentiation phenotype of $\mathrm{H} 6 \mathrm{O}$, whereas gene expression analysis of the Lam-I culture indicates a putative stem-cell-like phenotype in comparison to those cultured on other substrates (Fig. 4b). The enhanced expression of certain stem-cell-related genes in Fn and Lam-I cultures further triggered us to analyze the expression of EMT-related genes in these cells. We observed that genes like Snail, Twist, Zeb1, and Cdh2 were highly expressed in the Fn culture with respect to the TCP control, which are well known EMT inducers (Fig. 4c). The EMT like phenotype has been reported to be the traits of CSCs that are induced by the TGF- $\beta$ signaling. ${ }^{19}$ Keeping this in mind we also tested several TGF- $\beta$ responsive genes like Foxc $2,{ }^{20}{ }^{2} l 6^{21}$ and $P a i^{22}$ (Fig. $4 \mathrm{~d}$ ). 
a.

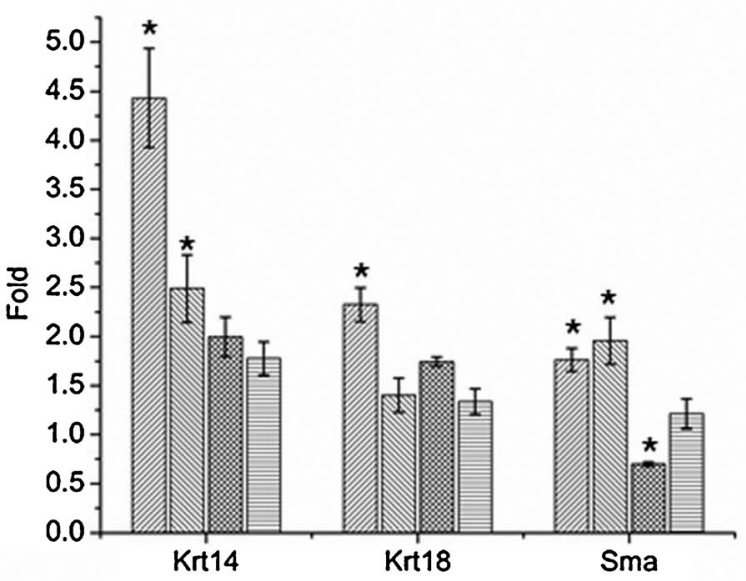

C.

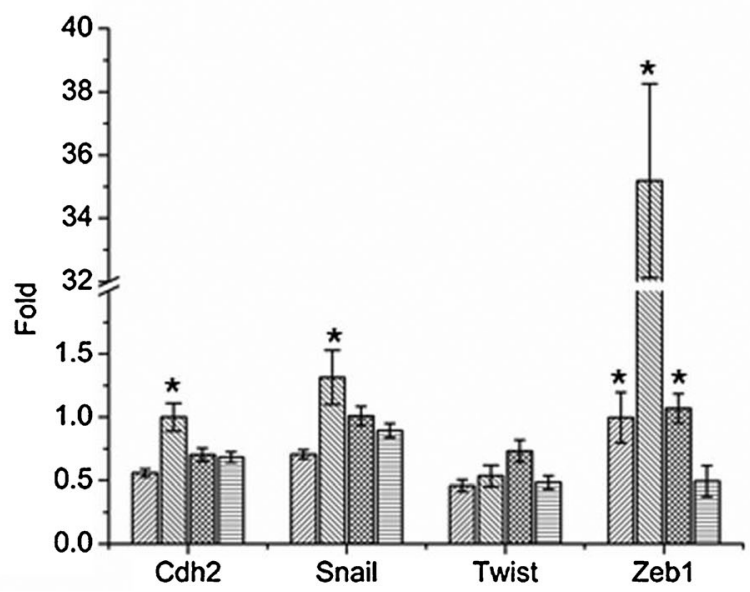

b.

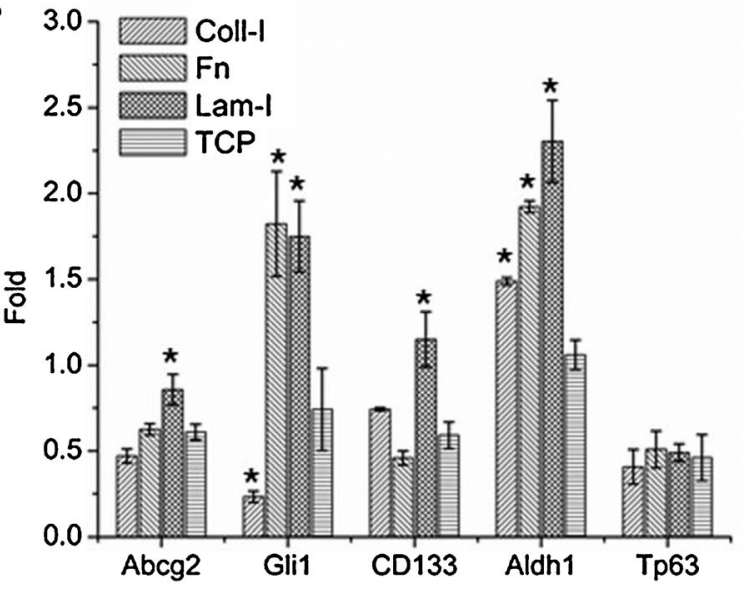

d.

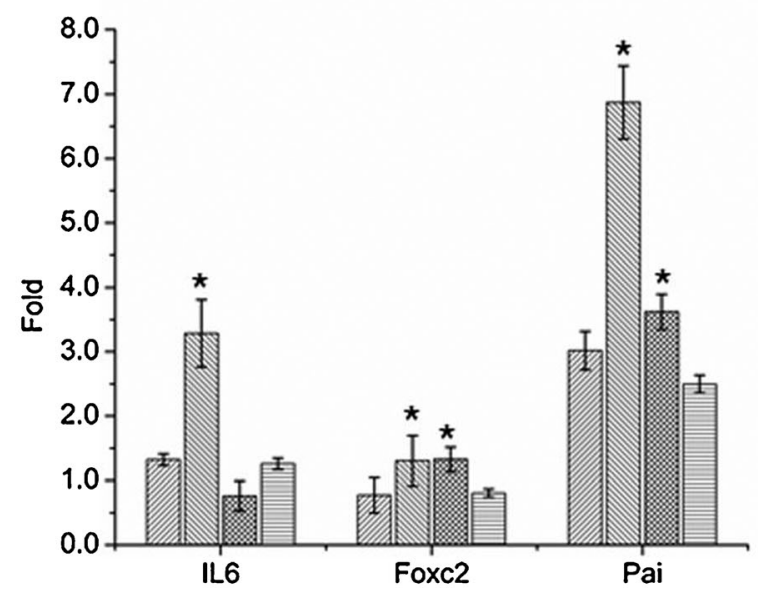

Fig. 4 Quantitative real-time reverse transcription PCR analysis of gene expression in Coll-I Fn and Lam-I cultures compared to the TCP control: (a) differentiation markers, (b) stem cell markers, (c) EMT markers and (d) TGF- $\beta$ downstream genes associated with EMT. Each expression was normalized using Gapdh as the internal control. $\left({ }^{*}\right) p<0.05$ obtained from the 'pair wise fixed reallocation randomization test' represents significant difference between cells on coated substrates and TCP control.

Two of these genes (Il6 and Pai) were observed to be up-regulated in the Fn culture, suggesting that an EMT like phenotype was induced in the Fn culture. Together, we have demonstrated that TICs acquire a differentiation phenotype on Coll-I substrates, whereas they retain majorly stem-cell traits on Lam-I. Considerable increase in the EMT-related genes clearly shows an attainment of invasive phenotype by the TICs when cultured on Fn coated substrates.

\section{Discussion}

Recent evidences from the literature validate ECM not only as a mere physical scaffold but also as an influential regulator in cell behaviour. A bidirectional crosstalk exists between the cell and its immediate surrounding ECM, whether secreted endogenously or supplied from outside, where the ECM influences gene expression and the cell, in turn, can remodel the ECM, which then further acts on the cell creating a feedback loop. ${ }^{23}$ The cell senses this ECM structure with the help of a family of heterodimeric transmembrane proteins called integrins, which can direct ECM derived signals to the cell and give rise to cell-specific functions. These phenomena have been accomplished in the mammary gland both during morphogenesis and tumorigenesis.

Data suggest that type-I collagen mediates ductal morphogenesis, and collagen derived signals are critical for primary branching and for basement membrane production during mammary gland development. ${ }^{24}$ Extracellular protein laminin-I signalling is also crucial during lactation and for inducing tissue specific function in the mammary gland. ${ }^{25}$ Also, mammary epithelial specific stem cells exist throughout the gland's lifetime and reside in a unique niche in the terminal ducts next to differentiated cells. Not much work has been done to evaluate the role of ECM in this niche which modulates cell-ECM interaction in maintaining quiescence or differentiation in a particular lineage. CSCs (or TICs) may also reside in such microenvironment in contact with fully differentiated cells, but yet maintains their progenitor phenotype. During tumorigenesis restructuring of the ECM takes place, allowing deposition of a large amount of collagen-I, enhanced fibronectin accumulation and loss of laminin signalling which stimulates formation of 
a reactive environment. ${ }^{26-28}$ Failure of the cells to systematically interpret compositional alterations in the surrounding ECM gives rise to malignant transformation. In our work we isolated the TIC population from a Her2/neu-induced mouse mammary tumour using an expression using two integrins markers CD61 ( $\beta 3$ ) and CD49f ( $\alpha 6)$ to address how TICs respond to different extracellular cues provided by the extracellular matrix proteins present in the immediate tumour surrounding and determine its fate.

Coll-I and Fn promoted adhesion of the sorted TICs in a monolayer whereas Lam-I inhibited growth in a monolayer and forced the cells to form a clustered structure. Detachment of cells with trypsin from Lam-I substrates took only 5 minutes while it took almost 10 minutes on other substrates, suggesting cells on Lam-I were loosely attached in comparison to other ECM proteins. The reduced adhesion of breast cancer cells to Lam-I has been previously reported in MCF-7 cells. ${ }^{29}$ It was observed that the sorted cells on Coll-I, Fn and TCP showed proliferation rate twice as much to Lam-I. This also suggests that Lam-I maintains the TICs in a slower proliferating state. Similar observation was obtained previously from the study of mammary stem cells in a laminin rich environment. ${ }^{30,31}$ Although decreased adhesion was observed in Lam-I, interestingly this substrate maintained the majority of the TIC population of Her2overexpressing breast tumour cells. The percentage of the CD49f ${ }^{\text {high }}$ CD61 ${ }^{\text {high }}$ cell population in sorted cells cultured on Lam-I coated substrates for 1 week was $49.9 \%$, which was maintained till 2 weeks $(49.1 \%)$ of culture. This can be partially attributed to the lower adhesion and proliferation of the cells in Lam-I substrates as the literature reports that stem cells are known to remain in a more quiescent state and hence maintain their selfrenewal characteristics. ${ }^{30}$ The maintenance of stemness in the Lam-I substrates has been confirmed by the enhanced clonogenic potential and tumorsphere formation ability of these cells.

Cells from Lam-I substrates not only gave rise to more number of colonies but also showed colonies with larger dimensions in comparison to those on other ECM proteins. Gene expression profiling results also showed that cells from Lam-I cultures displayed higher expression of stemness related genes like Abcg2, CD133, Gli1 and Aldh1. Microenvironmental cues are transmitted from the matrix to the cell via integrins which undergo allosteric changes triggering cell signalling pathways. $^{32}$ Laminin signalling has been shown to be important in mammary gland development and tumorigenesis. ${ }^{9}$ In this respect $\alpha 6 \beta 1$ is the most studied integrin. ${ }^{33}$ In our study we have observed the significant up-regulation in mRNA expression of CD49f ( $\alpha 6), \beta 1, \alpha \mathrm{V}$ and CD61 ( $\beta 3)$ in the Lam-I culture compared to the control TCP (Fig. S4, ESI $\dagger$ ). Although the $\alpha 6 \beta 1$ dimeric complex has been well known in laminin interaction, $\alpha v \beta 3$ interaction to laminin was demonstrated in human vascular endothelial cells. ${ }^{34}$ This indicates that interaction between these integrins might play a critical role in integrinmediated laminin signalling. The enhanced tumorigenic property of the TICs in Lam-I and stemness maintenance could be accounted by the interaction of Lam-I with $\beta 3$ integrin.

The TIC population on Fn showed similar attachment and proliferation as the control TCP culture. Interestingly the percentage of the CD49 $\mathrm{f}^{\text {high }} \mathrm{CD} 61^{\text {high }}$ cell population after 1 week of culture was $16 \%$ higher than that from the TCP culture which was maintained till week 2. Also, clonogenic potential was significantly higher in the Fn culture in comparison to the TCP control, but no significant increment was observed in tumorsphere formation after week 1. Gene expression analysis of mRNA levels of Gli1 and Aldh 1 suggests that a considerable amount of the TIC population is still retained by the Fn substrates. Role of fibronectin in mammary gland development is not widely studied but fibronectin deposition has been observed in breast cancer development and tumour invasion. Our study also reveals that TICs in an Fn-rich environment showed enhanced expression of Zeb1, a transcriptional protein associated with breast cancer metastasis, ${ }^{35}$ and minor upregulation of Snail and $C d h 2$. As cancer metastasis is said to occur by an epithelialto-mesenchymal transition and TGF- $\beta$ is also an effective inducer of EMT, ${ }^{36}$ we studied several downstream genes of the TGF- $\beta$ signalling pathways. The enhanced expression of Pai and Il6 suggests that the Fn scaffold promotes an EMT-like transition through the TGF- $\beta$ mediated pathway. This observation can be further explained by the enhanced expression in mRNA levels of $\alpha 5$ and $\beta 1$ integrins in sorted cells cultured in the Fn substrates (Fig. S4, ESI $\dagger$ ). The literature reports that these integrins, identified as major receptors of fibronectin may interact with the TGF- $\beta$ Receptor-II and play a major role in EMT induction. ${ }^{37}$

Coll-I substrates showed the minimum retention of the TIC population after one week of culture compared to the other ECM proteins. Clonogenic and mammosphere formation studies revealed that the cells on the Coll-I culture significantly lost their tumorigenic potential. Apart from Aldh1 expression all the other stem cell markers were shown to be down-regulated in the Coll-I substrates. On the other hand up-regulation of differentiation markers, Krt18 and Krt14, suggests that cells are undergoing a differentiation phenotype in Coll-I substrates. Literature reports supported that collagen-I substrates can induce differentiation in mammary progenitor cells D290 in vitro cultures and regulate expression of Krt14 and Krt 18 drastically. ${ }^{30}$ In vitro tumorigenic assays also signify loss in stemness accompanied with enhanced differentiation on the collagen scaffold, yet no significant increase in $\alpha 1, \alpha 2$ and $\beta 1$ integrins was observed in mRNA expression levels (Fig. S4, ESI $\dagger$ ).

\section{Experimental}

\section{Cell isolation and culture}

H6O5 cells were isolated from a primary mammary tumor using the protocol previously described ${ }^{38}$ and maintained in DMEM/F12 (Invitrogen, CA, USA), supplemented with $2 \mathrm{mM}$ L-glutamine and $10 \mathrm{mg}$ per $\mathrm{mL}$ of insulin (Sigma) in a $5 \% \mathrm{CO}_{2}$ humidified incubator at $37{ }^{\circ} \mathrm{C}$. $\mathrm{H} 6 \mathrm{O} 5$ was enriched for CD49 ${ }^{\text {high }}$ CD61 ${ }^{\text {high }}$ subpopulation using fluorescence assisted cell sorting (FACS, Fig. 1a). Sorted cells were immediately seeded on Coll-I, Fn, TCP at a density of $50 \mathrm{~K}$ cells per $\mathrm{cm}^{2}$ and at $100 \mathrm{~K}$ cells per $\mathrm{cm}^{2}$ for Lam-I. Cells were maintained in ECM coated plates for one to two weeks and analyzed.

\section{Preparation of ECM coated substrates}

Collagen-I (rat tail) and fibronectin (human) were coated on tissue culture polystyrene at a concentration of $0.1 \mathrm{mg} \mathrm{mL}^{-1}$ and $20 \mu \mathrm{g} \mathrm{mL}^{-1}$, respectively, for $1 \mathrm{~h}$ at $37^{\circ} \mathrm{C}$. All ECM proteins were obtained from BD biosciences. Laminin-I (mouse) $\left(20 \mu \mathrm{g} \mathrm{mL}^{-1}\right)$ 
was coated on a poly-D-lysine $\left(M_{\mathrm{w}}=500-550 \mathrm{kDa}, \mathrm{BD}\right.$ Biosciences) precoated Tissue Culture Plastic (TCP) for $1 \mathrm{~h}$ at $37{ }^{\circ} \mathrm{C}$, rinsed with deionized $\mathrm{H}_{2} \mathrm{O}$, air dried in a laminar flow hood and stored at $4{ }^{\circ} \mathrm{C}$ prior to cell seeding. Homogeneity and uniform coating for each ECM proteins were confirmed using water contact angle measurements taken from random area for $n=5$ and indicated as average in Table S1 (ESI $\dagger$ ). Using polyD-lysine is a standard practice and has been extensively used to facilitate adhesion of bioactive molecules for cell culture. ${ }^{39,40}$ As a control study we also tested the morphology of $\mathrm{H} 6 \mathrm{O} 5$ cells and MCF-7 cells on poly-D-lysine coated TCP and uncoated TCP.

\section{Flow cytometry analysis and sorting}

Flow cytometry was performed using an FC500 CXP flow cytometer (Beckman Coulter, Fullerton, CA, USA). At least 20000 events were acquired for each sample, cell debris were gated out by forward and side scatter profiles. The antibodies used were PE-conjugated anti-CD49f $(0.5 \mu \mathrm{g}$ for 106 cells in $100 \mu \mathrm{L}$ volume) and Alexa Fluor 488 conjugated anti-CD61 (1 $\mu \mathrm{g}$ for $10^{6}$ cells in $100 \mu \mathrm{L}$ volume) obtained from BioLegend, SanDiego, CA, USA. At $80 \%$ confluency $\mathrm{H} 6 \mathrm{O} 5$ was detached from culture plates using Accutase (Invitrogen), passed through a $40 \mu \mathrm{m}$ nylon mesh (Fisher Scientific) to obtain single cells and suspended in FACS buffer (PBS, 2\% FBS) at $1 \times 10^{6} \mathrm{~mL}^{-1}$ and incubated with indicated antibodies for 30 minutes on ice. Cells were washed thrice with FACS buffer prior to analysis. Cell sorting was carried out on a FACSAria II cell sorter (Becton Dickinson). Results were analysed using WinMDI 2.9 software.

\section{In vitro clonogenic assay}

$\mathrm{H} 6 \mathrm{O} 5$ cells were detached from ECM coated plates and reseeded in six-well tissue culture plates at a density of 500 cells per well in complete medium. After 10 days, colonies were fixed with $4 \%$ paraformaldehyde and stained with $0.1 \%$ crystal violet. Colonies with sizes greater than $0.5 \mathrm{~mm}$ in diameter were counted.

\section{In vitro mammosphere-tumorsphere formation assay}

$\mathrm{H} 6 \mathrm{O} 5$ cells were detached from ECM coated plates and rinsed with serum free media, plated in low attachment 12-well plates (NUNC, Germany) at a density of 20000 cells per $\mathrm{mL}$ in serum-free DMEM/F12 medium (Invitrogen, CA, USA) supplemented with $20 \mathrm{ng} \mathrm{mL}^{-1}$ epidermal growth factor (Sigma,

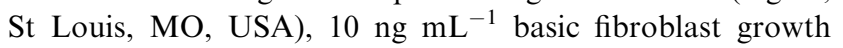
factor (Sigma), $5 \mathrm{mg} \mathrm{mL}^{-1}$ insulin (Sigma), B-27 supplement (1: 50 dilution, Invitrogen) and $0.4 \%$ bovine serum albumin (Sigma). Cells were cultured under $5 \% \mathrm{CO}_{2}$ at $37{ }^{\circ} \mathrm{C}$ for a week.

\section{RNA extraction and quantitative real-time reverse transcriptase PCR}

Total RNA was extracted using an RNeasy mini purification kit (Qiagen), and subsequently reverse-transcribed with a $\mathrm{qScript}^{\mathrm{TM}}$ cDNA synthesis kit (Quanta Biosciences Inc.). RT-qPCR was carried out for 45 cycles of PCR $\left(95{ }^{\circ} \mathrm{C}\right.$ for $15 \mathrm{~s}, 60{ }^{\circ} \mathrm{C}$ for $15 \mathrm{~s}$ and $72{ }^{\circ} \mathrm{C}$ for $30 \mathrm{~s}$ ) with iQ5 SYBR Green supermix (Biorad) using primers indicated in Table S2 (ESI $\dagger$ ). In a $25 \mu \mathrm{L}$ total volume of reaction mixture, $200 \mathrm{nM}$ of both forward and reverse primers (Integrated DNA Technologies, Inc.) and $1 \mu \mathrm{g} \mathrm{mL} \mathrm{m}^{-1}$ of cDNA template at a final concentration were employed. Data analysis was performed for triplicate measurements using a $2^{-\Delta \Delta C T}$ method for relative quantification $^{41}$ and all samples were normalized to Gapdh expression as the internal control.

\section{Statistical analysis}

All assays were performed in triplicates. Data are indicated as mean \pm standard deviation. Comparisons between two groups were done using paired student's $t$-test. $(*) p<0.05$ was considered as significant. Gene expression was normalized and analyzed using a "pair wise fixed reallocation randomization test ${ }^{42}$ on each sample and a value of $p<0.05$ was considered as significant.

\section{Conclusions}

Herein, we have demonstrated that TICs derived from Her2/ neu-induced mammary tumour cells show flexibility in response to various microenvironments. Different ECM proteins can influence the behaviour of cancer stem cells as evidenced from the functional properties of the cells as well as their gene expression pattern. Our results showed that Lam-I maintains the majority of the TIC population and Fn induces an EMTlike phenotype, whereas Coll-I triggers a differentiation phenotype. Furthermore, we conducted an additional experiment with a well-studied human breast cancer cell model MCF-7. This cell line has been shown to possess a side population of cells with cancer stem cell phenotype identified with the CD $44^{\text {high }} \mathrm{CD} 24^{\text {low }}$ expression level when propagated under suspension culture. ${ }^{1,43}$ We investigated the effect of ECM proteins on this human breast cancer cell line and our preliminary data demonstrate similar changes in morphology followed by an increase in the $\mathrm{CD} 44^{\text {high }} \mathrm{CD} 24^{\text {low }}$ population, as observed with $\mathrm{H} 6 \mathrm{O} 5$ when cultured on laminin coated matrices in comparison to the TCP control (Fig. S5, ESI $\dagger$ ). Hence this result correlates to our hypothesis that laminin maintains or in other words increases the tumour-initiating cell population. The results of this work will help us to determine specific cancer stem cell responses like lineage maintenance, differentiation or other phenotypic transitions through cell-matrix interactions, henceforth provide better understanding of the tumour microenvironment and thus help us design suitable treatments.

\section{Acknowledgements}

We gratefully acknowledge the financial support of this work by NIH grant (3P20RR017698-08) to HC and QW, and the American Cancer Society Research Award (RSG-10-067-01-TBE) to HC. QW would also like to acknowledge the support from the US NSF CHE-0748690, the Alfred P. Sloan Scholarship, and the Camille Dreyfus Teacher Scholar Award.

\section{References}

1 M. Al-Hajj, M. S. Wicha, A. Benito-Hernandez, S. J. Morrison and M. F. Clarke, Proc. Natl. Acad. Sci. U. S. A., 2003, 100, 3983-3988.

2 R. P. Hill and R. J. Perris, J. Natl. Cancer Inst., 2007, 99, 1435-1440.

3 M. F. Clarke, J. E. Dick, P. B. Dirks, C. J. Eaves, C. H. M. Jamieson and D. L. Jones, et al., Cancer Res., 2006, 66, 9339-9344.

4 J. B. Sneddon and Z. Werb, Cell Stem Cell, 2007, 1, 607-611. 
5 J. E. Visvader and G. J. Lindeman, Nat. Rev. Cancer, 2008, 8, 755-768.

6 T. Reya, S. J. Morrison, M. F. Clarke and I. L. Weissman, Nature, 2001, 414, 105-111.

7 K. A. Moore and I. R. Lemischka, Science, 2006, 311, 1880-1885.

8 M. Smalley and A. Ashworth, Nat. Rev. Cancer, 2003, 3, 832-844.

9 C. Ghajar and M. J. Bissell, Histochem. Cell Biol., 2008, 130, $1105-1118$.

10 P. Monaghan, M. J. Warburton, N. Perusinghe and P. S. Rudland, Proc. Natl. Acad. Sci. U. S. A., 1983, 80, 3344-3348.

11 P. Schedin and P. J. Keely, Cold Spring Harbor Perspect. Biol., 2011, 3, a003228.

12 P. K. Lo, D. Kanojia, X. Liu, U. P. Singh, F. G. Berger and Q. Wang, et al., Oncogene, 2012, 31, 2614-2626.

13 S. K. Singh, T. D. Clarke, M. Terasaki, V. E. Bonn, C. Hawkins and J. Squire, et al., Cancer Res., 2003, 63, 5821-5828.

14 S. Claudinot, M. Nicolas, H. Oshima, A. Rochat and Y. Barrandon, Proc. Natl. Acad. Sci. U. S. A., 2005, 102, 14677-14682.

15 C. Ginestier, M. H. Hur, E. Charafe-Jauffret, F. Monville, J. Dutcher and M. Brown, et al., Cell Stem Cell, 2007, 1, 555-567.

16 M. Wright, A. Calcagno, C. Salcido, M. Carlson, S. Ambudkar and L. Varticovski, Breast Cancer Res., 2008, 10, R10.

17 T. Ishikawa and H. Nakagawa, J. Exp. Ther. Oncol., 2009, 8, 5-24.

18 S. Liu, G. Dontu, I. D. Mantle, S. Patel, N. S. Ahn and K. W. Jackson, et al., Cancer Res., 2006, 66, 6063-6071.

19 R. Kalluri and R. A. Weinberg, J. Clin. Invest., 2009, 119, 1420-1428.

20 S. A. Mani, J. Yang, M. Brooks, G. Schwaninger, A. Zhou and N. Miura, et al., Proc. Natl. Acad. Sci. U. S. A., 2007, 104, 10069-10074.

21 J. I. Park, M. G. Lee, K. Cho, B. J. Park, K. S. Chae and D. S. Byun, et al., Oncogene, 2003, 22, 4314-4332.

22 C. Yang, K. Patel, P. Harding, A. Sorokin and W. F. Glass, Exp. Cell Res., 2007, 313, 1240-1250.

23 M. J. Bissell, H. G. Hall and G. Parry, J. Theor. Biol., 1982, 99, 31-68.

24 P. J. Keely, A. M. Fong, M. M. Zutter and S. A. Santoro, J. Cell Sci., 1995, 108, 595-607.
25 C. H. Streuli, C. Schmidhauser, N. Bailey, P. Yurchenco, A. P. Skubitz and C. Roskelley, et al., J. Cell Biol., 1995, 129, 591-603.

26 N. Thomasset, A. Lochter, C. J. Sympson, L. R. Lund, D. R. Williams, O. Behrendtsen, Z. Werb and M. J. Bissell, Am. J. Pathol., 1998, 153, 457-467.

27 T. Gudjonsson, L. Ronnov-Jessen, R. Villadsen, F. Rank, M. J. Bissell and O. W. Petersen, J. Cell Sci., 2002, 115, 39-50.

28 M. Torbenson, J. Wang, M. Choti, R. Ashfaq, A. Maitra and R. E. Wilentz, et al., Mod. Pathol., 2002, 15, 826-830.

29 A. Noel, A. Calle, H. Emonard, B. Nusgens, J. M. Foidart and C. M. Lapiere, In Vitro Cell. Dev. Biol., 1988, 24, 373-380.

30 M. A. LaBarge, C. M. Nelson, R. Villadsen, A. Fridriksdottir, J. R. Ruth and M. R. Stampfer, et al., Integr. Biol., 2009, 1, 70-79.

31 O. W. Petersen, L. Ronnov-Jessen, A. R. Howlett and M. J. Bissell, Proc. Natl. Acad. Sci. U. S. A., 1992, 89, 9064-9068.

32 C. K. Miranti and J. S. Brugge, Nat. Cell Biol., 2002, 4, E83-E90.

33 S. M. Pontier and W. J. Muller, J. Cell Sci., 2009, 122, 207-214.

34 R. H. Kramer, Y. F. Cheng and R. Clyman, J. Cell Biol., 1990, 111, 1233-1243.

35 S. Spaderna, O. Schmalhofer, M. Wahlbuhl, A. Dimmler, K. Bauer and A. Sultan, et al., Cancer Res., 2008, 68, 537-544.

36 J. Song, Cell Res., 2007, 17, 289-290.

37 D. Wang, L. Sun, E. Zborowska, J. K. Willson, J. Gong and J. Verraraghavan, et al., J. Biol. Chem., 1999, 274, 12840-12847.

38 H. Chen, G. Pimienta, Y. Gu, X. Sun, J. Hu and M.-S. Kim, et al., Proteomics, 2010, 10, 3800-3810.

39 W. C. Chang and D. W. Sretavan, Langmuir, 2008, 24, 13048-13057.

40 E. M. Harnett, J. Alderman and T. Wood, Colloids Surf., B, 2007, 55, 90-97.

41 K. J. Livak and T. D. Schmittgen, Methods, 2001, 25, 402-408.

42 M. W. Pfaffl, G. W. Horgan and L. Dempfle, Nucleic Acids Res., 2002, 30, e36.

43 G. Dontu, W. M. Abdallah and J. M. Foley, Genes Dev., 2003, 17, 1253-1270. 